\title{
Tree growth and survival over 61 years at the Second International Larch Provenance Test in southeastern Michigan, USA
}

\author{
Daniel M. Kashian ${ }^{1 *}$ and Burton V. Barnes ${ }^{2} \dagger$ \\ ${ }^{1}$ Department of Biological Sciences, Wayne State University, Detroit, MI 48202 \\ ${ }^{2}$ School for Environment and Sustainability, University of Michigan, Ann Arbor, MI 48109 \\ * Corresponding author: Daniel M. Kashian, E-mail: dkash@wayne.edu
}

\begin{abstract}
Provenance trials remain an important tool for understanding genetic variation in forest trees. Maintaining decades-old experiments is critical for revealing maladaptation of translocated populations to local sites and meaningful divergence in survival and growth. We revisited the Second International Larch Provenance Test in southeastern Michigan, which featuring 24 provenances of European and Japanese larch. We compiled data collected when the plantation was 25,41 , and 61 years from seed to supplement data published at 19 years from seed. Divergence in survival rates first became pronounced at 41 years from seed. Plantation sources of unknown origin and continental Sudeten provenances had the highest rates of survival. High-elevation sources from the southern Alps performed the poorest. Survival differences were likely driven by ice storm damage and severe growing season droughts, both of which occurred at least 1-2 times per decade in southeastern Michigan over the last 60 years. Provenance performance for growth mirrored that of survival, although sources varied more in their survival than in their growth. Growth rate among sources varied over the 43-year sampling period, with intervals of fast growth occurring in several of the overall poor-performing provenances. Diameter was moderately correlated to both elevation and latitude, with inconsistent correlations to climatic variables. Broad geographical variation in provenance performance was also important in explaining variation in growth. Our data corroborate that monitoring of long-term provenance trials could be an important source of information needed to predict and understand how forest species may respond to imminent climate change and may be critical for developing strategies for its mitigation.

Keywords: provenance, seed source, geographic races, European larch
\end{abstract}

\section{Introduction}

Understanding how tree species vary genetically has long been a focus of forest ecology and silviculture (Nienstaedt 1979, McComb 1955, Cook 1955), and modern advances in genomics and genetic methodology have not diminished the usefulness of long-established field trials in examining genetic variation of forest trees. When natural populations are exposed to their environments for many generations, local populations of trees become well adapted to the sum total of the abiotic factors of a local site, including climate and soil moisture and the fluctuations they may experience over temporal scales of days to years or longer (Aitken et al. 2008, Savolainen et al. 2007, Barnes et al. 1998). As a general rule, movement of southern populations northward (or low-elevation populations to high elevations) often results in increased growth because they are adapted to a shorter critical daylength and thus cease their growth later in the fall. Survival of southern populations moved northward may be reduced if later growth into the fall also makes the translocated plants susceptible to frost damage (Barnes et al. 1998). Provenance testing emphasizes the movement of these populations over long distances and outside their region of origin such that the degree of the populations' adaptation to the new site is unknown (Morgenstern and Mullin 1990). Long-term provenance tests have been effective in elucidating differences among populations in growth rate (Lu et al. 2014, Wang et al. 2010, Morgenstern and Mullin 1990) but also drought tolerance (George et al. 2016, Gaspar et al. 2013, Arend et al. 2011), among other factors. Notably, many long-term trials have required several decades before provenances exhibited notable differences in tree performance, and these differences are thought to arise from occasional extreme climate events, particularly drought (Morgenstern and Mullin 1990, Campbell 1974, Namkoong et al. 1972). As such, 
short-term results are typically not sufficient to disclose differences among provenances (Morgenstern and Mullin 1990), but long-term provenance tests better indicate the suitability of the local populations in the new environment (Lu et al. 2016, Wang et al. 2010, Rehfeldt et al. 1999, Campbell 1979).

The idea that phenotypic variation among populations is driven by genetic as well as environmental variation has major implications for forest managers attempting to introduce populations to new environments, particularly in an era of climate change. Because populations have evolved such that their survival and growth are highly synchronized with local climate, information about these adaptations could improve managers' ability to predict how provenances may interact with similar climatic conditions well outside of their natural geographic range as well as with changing climatic conditions within it (Sang et al. 2019, Lu et al. 2014). Data from long-term provenance tests may therefore be critical for identifying ideal growing conditions for certain forest tree species (Wang et al. 2010, Thomson and Parker 2008, Wang et al. 2006, Rehfeldt et al. 1999). In turn, these data may be useful for climate change mitigation strategies in forest restoration such as intraspecific assisted migration (Lu et al. 2016, Leech et al. 2011, Hamaan et al. 2011) or similar approaches. Notably, a growing body of evidence suggests that local adaptation of plant populations is not a certainty (Bucharova et al. 2017, Breed et al. 2013, Jones 2013, Hereford 2009, Leimu and Fischer 2008), although such data for tree species is less common. This potential for a lack of ubiquity in local adaptation further emphasizes a need to revisit long-term provenance trials (e.g., Oleksyn and Giertych 1984, Giertych and Oleksyn 1981) as an attempt to better understand survival and growth for long-lived species.

European larch (Larix decidua Mil.) is native to central Europe, primarily at high elevations in the Alps, Carpathians, and Sudetes, but has been planted widely across central Europe, the United Kingdom, and the northeastern United States (Gilmore and David 2002, Barnes 1977). European larch has been used extensively in Europe for soil and steep-slope stabilization due to its rapid early growth and ability to colonize and tolerate harsh environments (George et al. 2016, Pâques et al. 2013). In addition, the species' superior form, high quality wood, and desirable aesthetic qualities have contributed to its wide introductions outside of its native range (Pâques et al. 2013, Hunt 1932). Larch plantations were established in the northeastern United States to take advantage of the species' impressive height and volume growth for timber production (Gilmore and David 2002). European larch has been grown mostly with Japanese larch (L. kaempferi (Lamb.) Carrière) and the Dunkeld hybrid larch (Larix $\times$ marschlinsii Coaz), both of which have similar characteristics (Barnes 1977). It has been used widely in provenance trials since the turn of the $20^{\text {th }}$ century (see Giertych and Oleksyn 1981, Schober 1976) presumably because of its large but fragmented native range in Europe. Recent phylogeographic analyses suggest that European larch survived in as many as six refugia during the last glacial period resulting in strong genetic differentiation (Wagner et al. 2015 a, 2015b). This genetic variation may be expressed as variability of drought tolerance among and within provenances of the species (George et al. 2016) and lends credence to previous assumptions of the likelihood of local adaptation. European larch is often classified into five broad groups: alpine larch, highly variable and found across the Alps in northern Italy, southern France, Switzerland, and Austria; Sudeten larch, less variable than alpine larch and found in a small region along the Czech Republic-Poland border; Tatra larch, occurring along a considerable range of elevations in northern and northeastern Slovakia; Polen larch, a lowland group found in southern Poland; and Romanian larch, scattered in small pockets across the Carpathian Mountains in northern Romania (Pâques et al. 2013).

A major investigation of the geographic variability of European larch was organized by the International Union of Forest Research Organizations (IUFRO) as two international provenance trials. The second of these trials was organized by Schober $(1985,1977)$ and examined 68 provenances from across the native range evaluated across 14 European countries and the United States. The objective of these trials was to document how the provenances responded to variable site conditions across Europe and the US and to identify genetic variability for adaptive traits across the native geographic range (Pâques et al. 2013), with a larger goal of identifying candidate provenances for breeding and outplanting. Dr. S.H. Spurr at the University of Michigan arranged participation in the Second International Larch Provenance Test beginning in 1958, in which 24 of the 68 provenances (alpine and Sudeten larch) were tested with Japanese larch and the Dunkheld hybrid larch in southeastern Michigan. Results from the international trial (age approximately 20 years) showed significant differences in survival and growth among provenances, with the best performances in growth occurring in provenances from central Europe, followed by the northern Alps; provenances from the southwestern Alps were the poorest performers (Schober 1981, 1977). Survival was found to be lowest in the Alpine provenances (Schober 1981, 1977). Specific to the Michigan trial, at 19 years from seed, provenances taken from plantation sources with unknown origins (the plantations were located at two maritime sites in Germany and one continental site in the Czech Republic) exhibited the best growth, as did native continental provenances from the Czech Republic; high-elevation provenances from Austria, Italy, and France exhibited the poorest growth (Barnes 1977). Differences in survival were too premature to discern a pattern (Barnes 1977). Notably, results from the Michigan trial as well as the overall international trial were reported before the plantings were halfway to the rotation age, which may be premature in making definitive conclusions from provenance trials of forest trees (Morgenstern and Mullin 1990). The objective of this study, therefore, was to provide the results of the Michigan trial at additional ages (ages 25,41 , and 61 ) to those reported by Barnes (1977) as an attempt to provide long-term trends in growth and to better identify potential patterns in survival among the provenances. 


\section{Methods}

\section{Study site}

Both provenance tests are on a site in southeastern Michigan on forest property of the University of Michigan near Pinckney, Michigan $\left(42.4269^{\circ},-83.9034^{\circ}\right)$. The climate is considered continental and slightly modified by the Great Lakes. Approximately $50 \%$ of the mean annual precipitation $(770 \mathrm{~mm}$ ) falls during the growing season; mean annual air temperature is $9.3^{\circ} \mathrm{C}$ and the mean temperature from May to September is $19^{\circ} \mathrm{C}$. The soil is glacial outwash characterized by a sandy loam texture, and the elevation is $268 \mathrm{~m}$ (Barnes 1977); site conditions are generally poor and droughty. Both sites remain dominated by planted larch but have experienced significant ingrowth of white pine (Pinus strobus L.) from surrounding plantings and invasion by black cherry (Prunus serotina Ehrh.), American elm (Ulmus americana L.), and Norway maple (Acer platanoides L.) since the establishment of the planting trials.

\section{Experiment I}

The first of two experiments was established in 1960. At that time, 12 provenances were selected: 10 of European larch, 1 of Japanese larch, and 1 of progeny of the Dunkeld hybrid larch collected from a Danish stand of Dunkeld hybrid larches in the Boller District of Denmark (Table 1). Of the ten European provenances, six originate from near the center of the species' native distribution in what Pâques et al. (2013) characterized as the central Alps (sources 2, 12,15) or eastern/northeastern Alps (sources 3, 5, 7). Two provenances were Sudeten and originated from lowland continental sources in the Czech Republic (sources 39 and 40), one from the lowlands of central Germany (source 28), and one from a maritime region of northern Germany (source 34; Table 1, Figure 1). Both German provenances originated from seeds collected from a plantation of an unknown source.
Experiment I was established with two-year-old seedlings (2-0 stock) planted at a spacing of $2.4 \times 2.4$ meters in a randomized complete-block design with two replicates (Barnes 1977). Each block contained 12 plots with 6 rows of 12 trees each (72 total trees per plot, 144 per provenance). The entire experiment was surrounded by two border rows of Dunkeld larch, and has been measured but not appreciably maintained since the late 1970s. Total tree height was measured each year between 1960 and 1967; beginning in 1976 tree diameter at breast height $(\mathrm{DBH})$ was measured rather than tree height and is reported in this study. Diameter at breast height was measured in Experiment I in winter 1976-77 (19 years from seed) by Barnes (1977); subsequent measurements occurred in spring 1983 (25 years from seed), fall 1999 (41 years from seed), and fall 2019 (61 years from seed). Percent survivorship of trees in 1983,1999 , and 2019 was also calculated for each source.

\section{Experiment II}

The second experiment was established in 1961, using a total of 20 provenances (Table 2). In addition to 8 provenances utilized in Experiment I (sources 3, 7, 28, 34, 36, 39, 40), 12 additional provenances were selected from European sources (Table 2). Ten of these sources originated from the core of the species' native distribution in the southern Alps (Pâques et al. 2013; sources $16,18,19,20,21,22,23,24,26,38)$. The remaining provenances included one from the northern/northeastern Alps (source 8) and a continental plantation source originating from seeds collected from an unknown source (source 30; Figure 1).

Table 1

Provenance information for 12 larch populations planted for Experiment I in southeastern Michigan, USA.

\begin{tabular}{|c|c|c|c|c|c|}
\hline $\begin{array}{l}\text { Source } \\
\text { Number }\end{array}$ & Provenance & Seed Source & Elevation (m) & Latitude & Longitude \\
\hline 2 & Schönweis & Austria & 1100 & $47^{\circ} 12^{\prime}$ & $10^{\circ} 40^{\prime}$ \\
\hline 3 & Mühldorf & Austria & 900 & $46^{\circ} 52^{\prime}$ & $13^{\circ} 21^{\prime}$ \\
\hline 5 & Langau 59 & Austria & $1000-1100$ & $47^{\circ} 51^{\prime}$ & $15^{\circ} 12^{\prime}$ \\
\hline 7 & Langau 38/41 & Austria & 1100 & $47^{\circ} 49^{\prime}$ & $15^{\circ} 10^{\prime}$ \\
\hline 12 & Sterzing/Flains & Italy & 1000 & $46^{\circ} 54^{\prime}$ & $11^{\circ} 26^{\prime}$ \\
\hline 15 & Ahrntal/Val Aurina & Italy & 1200 & $47^{\circ} 00^{\prime}$ & $12^{\circ} 00^{\prime}$ \\
\hline $28+$ & Schlitz 65 & Germany & 300 & $50^{\circ} 43^{\prime}$ & $9^{\circ} 31^{\prime}$ \\
\hline $34 \dagger$ & Neumünster & Germany & 50 & $54^{\circ} 15^{\prime}$ & $10^{\circ} 10^{\prime}$ \\
\hline 39 & Zabréh-Dubicko & Czech. & $450-550$ & $49^{\circ} 50^{\prime}$ & $16^{\circ} 58^{\prime}$ \\
\hline 40 & Ruda nad Moravou & Czech. & 480 & $49^{\circ} 59^{\prime}$ & $16^{\circ} 54^{\prime}$ \\
\hline 36 & Ina & Japan & 1200 & $35^{\circ} 52^{\prime}$ & $138^{\circ} 5^{\prime}$ \\
\hline -- & Dunkeld & Denmark, Distrikt of Boller1 & & & \\
\hline
\end{tabular}

${ }^{1}$ Progeny of the Dunkeld hybrid larch.

tSeeds obtained from a plantation; original source unknown. 


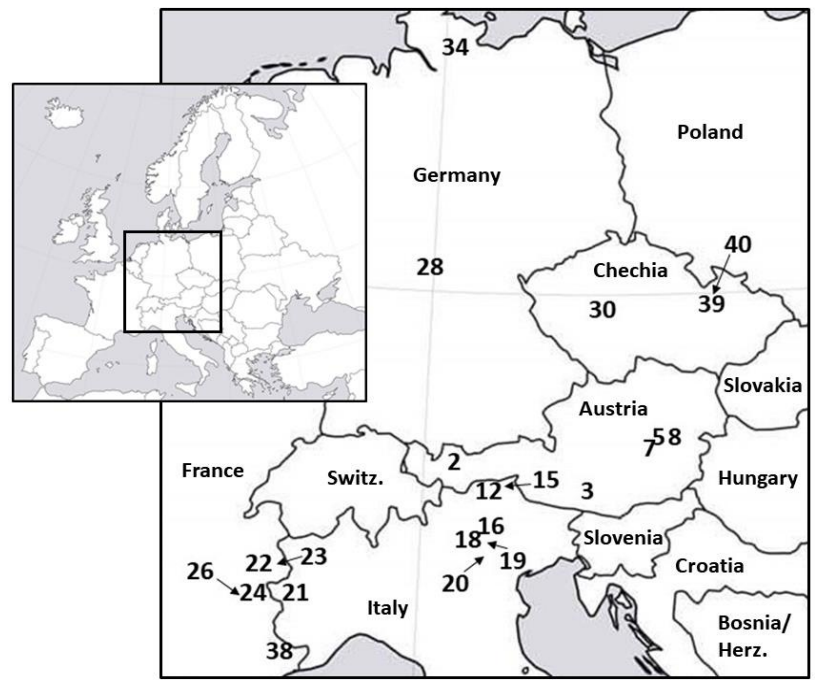

Figure 1

Source locations for 22 larch populations planted for Experiments I and II in southeastern Michigan, USA. Locations for the Dunkeld hybrid and source 36 (Ina, Japan) are not shown.
Experiment II was established with eight- three-year-old seedlings (2-1 stock) of each provenance planted at a spacing of 1.8 $x 1.8$ meters in a randomized complete-block design using four blocks (32 trees per provenance, 8 per block; Barnes 1977). Total tree height was measured each year between 1963 and 1965; thinning of this experimental planting was completed in 1969 whereby four trees of each source were randomly selected for removal in each block (resulting in a post-thinning total of 16 trees per provenance, 4 per block). Beginning in 1976 tree diameter $(\mathrm{DBH})$ was measured rather than tree height and is reported in this study. Similar to Experiment I, DBH was measured in Experiment II in winter 1976-77 by Barnes (1977), and subsequent measurements were made in spring 1983, fall 1999, and fall 2019. Percent survivorship was calculated for each source in 1983, 1999, and 2019.

\section{Data Analysis}

For both experiments, mean DBH was calculated for each source in each block for data collected in 1976, 1983, 1999, and 2019, and these values were converted to mean basal area. Basal area increment was calculated for the time periods 19761983, 1983-1999, and 1999-2019. Mean DBH values were compared among sources for the 1983, 1999, and 2019 data using one-way analysis of variance with Tukey post hoc tests for a randomized complete-block design, using block and provenance as effects without the interaction term.

Table 2

Provenance information for 20 larch populations planted for Experiment II in southeastern Michigan, USA.

\begin{tabular}{|c|c|c|c|c|c|}
\hline Source Number & Provenance & Seed Source & Elevation (m) & Latitude & Longitude \\
\hline 3 & Mühldorf & Austria & 900 & $46^{\circ} 52^{\prime}$ & $13^{\circ} 21^{\prime}$ \\
\hline 5 & Langau 59 & Austria & $1000-1100$ & $47^{\circ} 51^{\prime}$ & $15^{\circ} 12^{\prime}$ \\
\hline 7 & Langau 38/41 & Austria & 1100 & $47^{\circ} 49^{\prime}$ & $15^{\circ} 10^{\prime}$ \\
\hline 8 & Semmering & Austria & 1200 & $47^{\circ} 38^{\prime}$ & $15^{\circ} 46^{\prime}$ \\
\hline 16 & Cavalese & Italy & 1200 & $46^{\circ} 19^{\prime}$ & $11^{\circ} 27^{\prime}$ \\
\hline 18 & Tenna & Italy & 600 & $46^{\circ} 4^{\prime}$ & $11^{\circ} 19^{\prime}$ \\
\hline 19 & Pergine/Selvot & Italy & $1300-1400$ & $46^{\circ} 6^{\prime}$ & $11^{\circ} 23^{\prime}$ \\
\hline 20 & Cavedine & Italy & $600-700$ & $45^{\circ} 59^{\prime}$ & $11^{\circ} 4^{\prime}$ \\
\hline 21 & Pragelato & Italy & 1900 & $45^{\circ} 1^{\prime}$ & $6^{\circ} 56^{\prime}$ \\
\hline 22 & Embrun/Ristola & France & 1600 & $44^{\circ} 47^{\prime}$ & $6^{\circ} 57^{\prime}$ \\
\hline 23 & Embrun/Aiguilles & France & 1560 & $44^{\circ} 47^{\prime}$ & $6^{\circ} 54^{\prime}$ \\
\hline 24 & Briancon/Montgenevre & France & 1200 & $44^{\circ} 56^{\prime}$ & $6^{\circ} 43^{\prime}$ \\
\hline 26 & Briancon/de Villard & France & 1400 & $44^{\circ} 52^{\prime}$ & $6^{\circ} 39^{\prime}$ \\
\hline $28+$ & Schlitz 65 & Germany & 300 & $50^{\circ} 43^{\prime}$ & $9^{\circ} 31^{\prime}$ \\
\hline $30 \dagger$ & Dobřiš & Czech. & 500 & $49^{\circ} 47^{\prime}$ & $14^{\circ} 11^{\prime}$ \\
\hline $34+$ & Neumünster & Germany & 50 & $54^{\circ} 15^{\prime}$ & $10^{\circ} 10^{\prime}$ \\
\hline 36 & Ina & Japan & 1200 & $35^{\circ} 52^{\prime}$ & $138^{\circ} 5^{\prime}$ \\
\hline 38 & Valdeblore & France & $1700-1800$ & $44^{\circ} 14^{\prime}$ & $7^{\circ} 11^{\prime}$ \\
\hline 39 & Zabréh-Dubicko & Czech. & $450-550$ & $49^{\circ} 50^{\prime}$ & $16^{\circ} 58^{\prime}$ \\
\hline 40 & Ruda nad Moravou & Czech. & 480 & $49^{\circ} 59^{\prime}$ & $16^{\circ} 54^{\prime}$ \\
\hline
\end{tabular}

†Seeds obtained from a plantation; original source unknown. 
Data were log-transformed for Experiment I; no violations of the assumptions of normality and heteroscasdicity were noted in Experiment II and the data therefore were not transformed. The relationships between mean DBH and mean summer temperature, mean summer precipitation, minimum monthly average temperature, and maximum monthly average temperature for each provenance (www.en-climate-data.org, accessed 12-14-2020) were examined with Spearman rank correlations for sources with known origin. Relationships between mean DBH and elevation, latitiude, and latitude adjusted for elevation (100 m of elevation equals one degree of latitude; Wiersma 1963) for each provenance were examined with Spearman correlations for all four sample years for all European sources with known origin (i.e., excluding source 36 from Japan). Basal area was calculated from DBH for the four sample years, and mean basal area increment (BAl) was calculated for the periods 1976$1983,1983-1999$, and $1999-2019$ by dividing basal area by the number of years between sample years. Repeated-measures ANOVA was used to compare changes in DBH trends among sources over time including year and the interaction term (year * provenance) as within-subject effects, and provenance as the between-subject effect. Significant percent changes in BAI during these periods were also qualitatively identified as those greater or less than the mean \pm one standard deviation of the $\mathrm{DBH}$ values for all sources.

\section{Results}

\section{Experiment I}

For Experiment I, DBH differed by provenance in all four sample years, with source 28 (Schlitz, plantation source) the best performer (Table 3). The blocking factor was not significant in any of the four sample years. The same four sources remained the top performers in all four sample years except 2019: sources 3 (Mühldorf, eastern/northeastern Alps), 39 (Zabréh-Dubicko, Sudeten, continental), and 40 (Ruda nad Moravou, Sudeten, continental), in addition to source 28 . Likewise, sources 5 (Langau 59, higher elevation, northeastern Alps) and 7 (Langau 38/41, higher elevation, northeastern Alps) were among the poorest performers in all sample years (Table 3). Significant differences among all provenances in $1976(p<0.001)$ were primarily driven by the poor performance of sources 5 and 7. In 1983 ( $p<0.001)$, differences were again driven by source 7, as well as the good performance of source 28. Differences in growth among provences in $1999(p<0.001)$ were driven by the poor performance of sources 5,7 , and 15 and by the good performance of sources 28 and 40 . There were very few significant pairwise comparisons in 2019 although the full ANOVA model was significant $(p=0.021)$; these differences featured the strong performance of source 28 . Repeated measures ANOVA revealed a significant effect of year on DBH $(p<0.001)$ and provenance on DBH $(p<0.001)$, but no significant interaction term (year * provenance) for within-subjects effects for any of the three intervals, suggesting similar trends in $\mathrm{DBH}$ changes over time among provenances. Using basal area increment, source 28 showed growth higher than average between 1976 and 1983 (5.2\% change/year), but much slower than average between 1983 and 1999 (0.1 \% change/year; Table 4). Source 2 exhibited higher-than-average growth between 1983 and 1999 (1.7\% change/year). Between 1999 and 2019, sources 7 (2.0\% change/year) and 12 (1.8\% change/year) showed higher-than-average growth,while source 39 (1.0\% change/year) showed lower-than-average growth (Table 4).

The relationships between $\mathrm{DBH}$ and geographic variables, and between $\mathrm{DBH}$ and local climate data, were most important at the outset of the experiment but weakened or became nonsignificant by 2019. The correlation between elevation and DBH was negative and strongest in 1976 and $1983(r=-0.82)$, lower in 1999 ( $r=-0.78)$, but weaker by $2019(r=-0.57)$. Latitude was positively correlated with $\mathrm{DBH}$ and was significant only in $1976(r=0.5)$, but was strongly negatively correlated with DBH between 1976 and $1999(r=-0.9)$ when adjusted for elevation. Mean summer temperature was strongly to moderately correlated with DBH in $1976(r=0.86), 1983(r=0.8), 1999(r=$ $0.81)$, and $2019(r=0.73)$. Similarly, mean high summer temperature was positively correlated with $\mathrm{DBH}$ most strongly in 1976 and 2019 ( $r=0.89$ and 0.85 , respectively) but moderately in $1983(r=0.75)$ and $1999(r=0.76)$. Mean low winter temperature was positively correlated with DBH in $1976(r=0.73)$ and $1983(r=0.75)$, and stronger in $1999(r=0.84)$, but was not significantly correlated in 2019. Interestingly, mean summer precipitation was negatively correlated with DBH in 1976 ( $r=$ -0.73) and $2019(r=-0.78)$, but not significant in 1983 and 2019.

Tree survival (based on 144 trees per provenance) varied among sources across the sample period, decreasing from a mean of $89 \%$ in 1976 (Barnes 1977) to $62 \%$ by 2019 (Table 5). During the entire sample period, the highest survival was found in source 40, which decreased from $90 \%$ survival in 1976 to $82 \%$ in 2019. Initial survival in 1976 was highest in sources $28,39,15$, and 5 , but only source 40 retained relatively high survival through 2019. Source 3 had the lowest survival in 2019 (36\%), dropping precipitously from $78 \%$ in 1999. The lowest survival across all sample years was source 36 (Japanese larch), which had only $70 \%$ survival in 1976 (Barnes 1977) and decreased to $40 \%$ by 2019 . Notably, source 36 also exhibited the highest decrease in survival among all provenances between 1976 and 1983 (70\% to $62 \%$ ) and between 1983 and 1999 (62 $\%$ to $49 \%$ ). Large decreases in survival occurred in several sources sometime after 1999, when all larch had reached 50-60 years from seed. The largest decreases in survival between 1999 and 2019 occurred in the plantation sources (28 and 34), two high-elevation sources ( 5 and 15), and the continental sources (39 and 40). Remarkably, these six sources also had the highest rates of survival in 1999 (Table 5). Survival was not well correlated to most geographic or climatic variables in any sample year. Mean summer precipitation was negatively correlated to survival in $1983(r=-0.74)$ and $1999(r=-0.7)$, but there was no other significant correlation for any variable in any of the four sample years. 
Table 3

Diameter values $(\mathrm{cm})$ for larch sources in Experiment I, 1976-2019. Sources not connected by a vertical line are significantly different at $\mathrm{a}=0.05$.

\begin{tabular}{|c|c|c|c|c|c|c|c|c|c|c|c|}
\hline \multicolumn{3}{|c|}{$1976^{\star}$} & \multicolumn{3}{|c|}{1983} & \multicolumn{3}{|c|}{1999} & \multicolumn{3}{|c|}{2019} \\
\hline Source & $\mathrm{DBH}$ & Signif & Source & $\mathrm{DBH}$ & Signif & Source & $\mathrm{DBH}$ & Signif & Source & $\mathrm{DBH}$ & Signif \\
\hline $28^{+}$ & 12.8 & & $28^{+}$ & 16.8 & & $28^{+}$ & 17.1 & & $28^{+}$ & 21.9 & \\
\hline 40 & 12.5 & & 40 & 14.0 & & 40 & 16.9 & & 3 & 21.6 & \\
\hline 39 & 12.3 & & 3 & 13.8 & & 3 & 16.7 & & 36 & 20.8 & \\
\hline 3 & 12.3 & & 39 & 13.7 & & 39 & 16.7 & & 40 & 20.7 & \\
\hline $34+$ & 11.9 & & $34{ }^{+}$ & 13.5 & & 2 & 16.2 & & 12 & 20.7 & \\
\hline 36 & 11.8 & & 36 & 12.9 & & 36 & 15.9 & & 39 & 20.2 & \\
\hline Dunkeld & 11.7 & & Dunkeld & 12.8 & & $34{ }^{+}$ & 15.5 & & 2 & 20.2 & \\
\hline 12 & 11.5 & & 2 & 12.8 & & Dunkeld & 15.4 & & 15 & 20.2 & 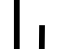 \\
\hline 2 & 11.4 & & 5 & 12.7 & & 12 & 15.3 & & $34+$ & 19.8 & \\
\hline 15 & 11.1 & & 12 & 12.5 & & 15 & 15.1 & & 5 & 19.6 & \\
\hline 5 & 11.0 & & 15 & 12.3 & & 5 & 14.6 & & 7 & 19.1 & \\
\hline 7 & 10.2 & & 7 & 11.2 & & 7 & 13.7 & & Dunkeld & 18.7 & \\
\hline
\end{tabular}

*Data from Barnes 1977.

†Seeds obtained from a plantation; original source unknown.

Table 4

Basal area increment and annual percent change values for larch sources in Experiment I, 1976-2019. *Denotes percent change values that fall outside the mean $\pm 1 \mathrm{SD}$.

\begin{tabular}{|c|c|c|c|c|c|c|}
\hline Source Number & $\begin{array}{c}1976-83 \mathrm{BAI} \\
(\mathrm{cm} 2 / \mathrm{yr} \times 1000)\end{array}$ & $\% \Delta / y r$ & $\begin{array}{c}1983-99 \mathrm{BAl} \\
(\mathrm{cm} 2 / \mathrm{yr} \times 1000)\end{array}$ & $\% \Delta / \mathrm{yr}$ & $\begin{array}{l}1999-2019 \text { BAI } \\
(\mathrm{cm} 2 / \mathrm{yr} \times 1000)\end{array}$ & $\% \Delta / y r$ \\
\hline $28+$ & 1.328 & $5.2^{*}$ & 0.050 & $0.1^{*}$ & 0.735 & 1.4 \\
\hline 3 & 0.439 & 2.0 & 0.434 & 1.3 & 0.737 & 1.5 \\
\hline 36 & 0.305 & 1.6 & 0.424 & 1.5 & 0.641 & 1.4 \\
\hline 40 & 0.446 & 2.0 & 0.440 & 1.3 & 0.561 & 1.1 \\
\hline 12 & 0.269 & 1.4 & 0.382 & 1.4 & 0.763 & $1.8^{*}$ \\
\hline 39 & 0.408 & 1.9 & 0.448 & 1.4 & 0.507 & $1.0^{*}$ \\
\hline 2 & 0.380 & 2.0 & 0.484 & $1.7^{*}$ & 0.572 & 1.2 \\
\hline 15 & 0.315 & 1.8 & 0.377 & 1.4 & 0.707 & 1.7 \\
\hline $34 t$ & 0.456 & 2.2 & 0.285 & 0.9 & 0.596 & 1.4 \\
\hline 5 & 0.452 & 2.6 & 0.255 & 0.9 & 0.672 & 1.7 \\
\hline 7 & 0.290 & 2.0 & 0.306 & 1.4 & 0.596 & $2.0^{*}$ \\
\hline Dunkeld & 0.302 & 1.6 & 0.360 & 1.3 & 0.442 & 1.1 \\
\hline
\end{tabular}

tSeeds obtained from a plantation; original source unknown. 
Table 5

Percent survival for larch sources in Experiment I, 1976-2019 ( $n=144$ trees for each provenance). CA=central Alps; EA=eastern/ northeastern Alps; SU=Sudeten.

\begin{tabular}{|c|c|c|c|c|c|}
\hline Source & Site & 19761 & 1983 & 1999 & 2019 \\
\hline 2 & High elevation; CA & 74 & 70 & 66 & 72 \\
\hline 3 & High elevation; EA & 90 & 86 & 78 & 36 \\
\hline 5 & High elevation; EA & 93 & 86 & 81 & 60 \\
\hline 7 & High elevation; EA & 79 & 76 & 73 & 73 \\
\hline 12 & High elevation; CA & 90 & 85 & 81 & 58 \\
\hline 15 & High elevation: CA & 94 & 86 & 81 & 63 \\
\hline $28+$ & Plantation & 97 & 90 & 88 & 65 \\
\hline $34+$ & Plantation & 92 & 87 & 84 & 51 \\
\hline 39 & Continental; SU & 95 & 90 & 85 & 69 \\
\hline 36 & Japanese larch & 70 & 62 & 49 & 40 \\
\hline 40 & Continental; SU & 92 & 88 & 85 & 82 \\
\hline Dunkeld & Hybrid larch & 88 & 83 & 76 & 69 \\
\hline Mean & & 89 & 82 & 77 & 62 \\
\hline
\end{tabular}

\section{Experiment II}

For Experiment II, source 39 (Zabréh-Dubicko, continental, Sudeten) was the best performer for growth in all sample years except 1976 (Table 6). As in Experiment I, the blocking factor was not significant in any sample year, and the same four sources $(28,30,39$, and 40$)$ remained among the top five performers in all four sample years. Sources 23 and 26 were among the poorest performers in all sample years, and source 21 was among the worst performers in all years except 2019 (Table 6). Significant differences among all provenances in 1976 ( $p<$ 0.001 ) were primarily driven by the poorest five performers (sources 21, 22, 23, 26, and 38). The best growth performers in 1976 (sources 28, 30, and 39) were also important drivers of the full ANOVA model, and in 1983 ( $p<0.001)$ differences were driven by the four worst performers (sources 21, 23, 26, and 38) and the two top performers (sources 30 and 39). Difference among provences in $1999(p<0.001)$ were driven by the poor performance of sources 7,23 , and 26 and by the good performance of source 39. As in Experiment I, there were relatively few significant pairwise comparisons in 2019 although the full ANOVA model was significant $(p<0.001)$; these differences featured the poor growth performances of sources 5 and 7 and the strong performance of source 39. Notably, source 26 which was an important poor performer in all other sample years - had no surviving trees by 2019. Similar to Experiment I, repeated measures ANOVA revealed a significant effect of year and provenance on DBH $(p<0.001)$ but an insignificant interaction term (year * provenance) for the three sampling intervals, suggesting similar trends in $\mathrm{DBH}$ changes over time among provenances. Using basal area increment, source 38 showed growth higher than average in every sampling interval: 3.8\% change/year between 1976 and 1983, $4.6 \%$ change/ year between 1983 and 1999, and $2.4 \%$ change/year between 1999 and 2019 (Table 7). Source 22 exhibited higher-than-average growth between 1976 and 1983, and between 1983 and 1999 (4.1\% change/year for each interval), source 21 showed higher-than average growth between 1983 and 1999 (3.1\% change/year), and source 24 showed higherthan-average growth between 1976 and 1983 (4.3\% change/ year). Sources 36 (1.5\% change/year) and 23 (1.1\% change/ year) showed lower-than-average growth between 1976 and 1983 , and source 5 (0.5\% change/year) showed lower-thanaverage growth between 1999 and 2019 (Table 7).

There was an overall moderate correlation between mean DBH and geographic variables that weakened by 2019. Elevation and DBH had a moderate correlation in $1976(r=-0.71)$ and $1983(r=-0.81)$ that weakened by $1999(r=-0.67)$ and was insignificant by 2019. The relationship between DBH and latitude was significant only in $1976(r=0.57)$ and $1983(r=0.7)$. Adjusting latitude for elevation strengthened its relationship with mean DBH in all years (1976: $-0.66 ; 1983: r=-0.74 ; 1999: r=$ $-0.67 ; 2019: r=-0.51)$. Most climate variables were not significantly correlated with mean DBH in all sample years except 1999, which featured significant correlatios between mean DBH and mean summer temperature $(r=0.5)$ and mean high summer temperature $(r=0.51)$.

Tree survival (based on 16 trees per provenance) decreased from a mean of $95 \%$ in 1976 to $55 \%$ in 2019 (Table 8). Three sources were notable for their high rate of survival during the 43-year sample period between 1976 and 2019: sources 18 (100\% survival until decreasing to $94 \%$ in 2019), 28 (100\% survival until deceasing to $81 \%$ in 2019) and 40 (100\% survival in 1976, then $94 \%$ survival thereafter). Sources 39 (94 $\%$ survival in all years until $88 \%$ in 2019) and 3 (94\% survival in 1976 , then $88 \%$ thereafter) also exhibited high survival. The lowest overall survival occurred in source 26 , which decreased sharply from $94 \%$ survival in 1983 to $44 \%$ in 1999 and was eliminated from the experiment by 2019 . Source 38 declined 
Table 6.

Diameter values $(\mathrm{cm})$ for larch sources in Experiment II, 1976-2019. Sources not connected by a vertical line are significantly different at $a=0.05$.

\begin{tabular}{|c|c|c|c|c|c|c|c|c|c|c|c|}
\hline \multicolumn{3}{|c|}{$1976^{*}$} & \multicolumn{3}{|c|}{1983} & \multicolumn{3}{|c|}{1999} & \multicolumn{3}{|c|}{2019} \\
\hline Source & $\mathrm{DBH}$ & Signif & Source & $\mathrm{DBH}$ & Signif & Source & $\mathrm{DBH}$ & Signif & Source & $\mathrm{DBH}$ & Signif \\
\hline $30^{+}$ & 14.1 & & 39 & 16.9 & & 39 & 20.7 & & 39 & 29.1 & \\
\hline $28^{+}$ & 13.9 & & $30^{+}$ & 16.1 & & $30^{+}$ & 20.2 & & $30^{+}$ & 27.9 & \\
\hline 39 & 13.9 & & 40 & 16.0 & & 18 & 20.1 & & 18 & 25.8 & \\
\hline 40 & 13.2 & & $28^{+}$ & 15.9 & & 40 & 20.0 & & $28^{+}$ & 25.7 & \\
\hline 3 & 13.2 & & 18 & 15.6 & 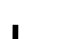 & 19 & 19.7 & & 40 & 25.2 & \\
\hline 18 & 13.1 & & 3 & 15.1 & & $28^{+}$ & 19.2 & & 3 & 25.2 & \\
\hline $34+$ & 13.0 & & 19 & 15.0 & & 3 & 18.2 & & 19 & 24.6 & \\
\hline 19 & 12.8 & & $34+$ & 14.4 & & $34+$ & 18.1 & & $34+$ & 23.9 & \\
\hline 8 & 11.7 & & 8 & 13.4 & 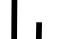 & 20 & 17.3 & & 22 & 22.8 & \\
\hline 16 & 11.6 & & 24 & 13.2 & & 22 & 16.9 & & 20 & 22.6 & \\
\hline 20 & 11.5 & & 16 & 13.1 & & 16 & 16.4 & & 21 & 22.4 & \\
\hline 36 & 11.2 & & 20 & 12.9 & & 24 & 15.9 & & 8 & 22.1 & \\
\hline 5 & 10.5 & 1 & 36 & 12.2 & & 8 & 15.3 & & 24 & 21.4 & \\
\hline 24 & 10.5 & & 5 & 12.2 & & 36 & 15.0 & & 38 & 20.7 & \\
\hline 7 & 9.6 & & 7 & 10.8 & & 5 & 14.4 & & 16 & 20.6 & \\
\hline 23 & 8.8 & & 22 & 10.2 & & 38 & 13.9 & & 36 & 19.7 & \\
\hline 22 & 8.2 & & 23 & 9.4 & & 21 & 13.5 & & 23 & 16.7 & \\
\hline 26 & 7.6 & & 21 & 9.0 & & 23 & 12.3 & & 7 & 16.4 & \\
\hline 21 & 7.4 & & 26 & 8.6 & & 7 & 12.2 & & 5 & 15.7 & \\
\hline 38 & 6.5 & & 38 & 8.0 & & 26 & 10.3 & & 26 & -- & \\
\hline
\end{tabular}

*Data from Barnes 1977.

† Seeds obtained from a plantation; original source unknown.

Table 7

Diameter, basal area increment, and annual percent change values for larch sources in Experiment II, 1976-2019. *Denotes percent change values that fall outside the mean \pm 1 SD.

\begin{tabular}{|c|c|c|c|c|c|c|}
\hline $\begin{array}{l}\text { Source } \\
\text { Number }\end{array}$ & $\begin{array}{c}1976-1983 \mathrm{BAl} \\
(\mathrm{cm} 2 / \mathrm{yr} \times 1000)\end{array}$ & $\% \Delta / \mathrm{yr}$ & $\begin{array}{c}\text { 1983-1999 BAI } \\
(\mathrm{cm} 2 / \mathrm{yr} \times 1000)\end{array}$ & $\% \Delta / \mathrm{yr}$ & $\begin{array}{c}\text { 1999-2019 BAI } \\
(\mathrm{cm} 2 / \mathrm{yr} \times 1000)\end{array}$ & $\% \Delta / y r$ \\
\hline 39 & 1.037 & 3.6 & 0.701 & 1.4 & 1.643 & 2.0 \\
\hline $30+$ & 0.677 & 2.4 & 0.731 & 1.6 & 1.454 & 1.9 \\
\hline 18 & 0.805 & 3.2 & 0.789 & 1.8 & 1.027 & 1.4 \\
\hline $28 \dagger$ & 0.669 & 2.4 & 0.569 & 1.3 & 1.146 & 1.7 \\
\hline 40 & 0.917 & 3.5 & 0.707 & 1.6 & 0.923 & 1.3 \\
\hline 3 & 0.603 & 2.4 & 0.507 & 1.3 & 1.193 & 1.9 \\
\hline 19 & 0.686 & 2.9 & 0.801 & 2.0 & 0.852 & 1.2 \\
\hline $34 \dagger$ & 0.430 & 1.8 & 0.590 & 1.6 & 0.957 & 1.6 \\
\hline 22 & 0.413 & $4.1^{*}$ & 0.891 & $4.1^{*}$ & 0.920 & 1.7 \\
\hline 20 & 0.383 & 2.0 & 0.652 & 2.1 & 0.830 & 1.5 \\
\hline 21 & 0.294 & 3.6 & 0.497 & $3.1^{*}$ & 1.255 & 1.8 \\
\hline 8 & 0.479 & 2.4 & 0.268 & 0.9 & 0.999 & 2.2 \\
\hline 24 & 0.718 & $4.3^{*}$ & 0.386 & 1.3 & 0.806 & 1.7 \\
\hline 38 & 0.244 & $3.8^{*}$ & 0.634 & $4.6^{*}$ & 0.924 & $2.4^{*}$ \\
\hline 16 & 0.416 & 2.2 & 0.478 & 1.6 & 0.610 & 1.3 \\
\hline 36 & 0.263 & $1.5^{*}$ & 0.374 & 1.4 & 0.640 & 1.6 \\
\hline 23 & 0.122 & $1.1^{*}$ & 0.309 & 1.9 & 0.501 & 1.8 \\
\hline 7 & 0.275 & 2.1 & 0.158 & 0.8 & 0.472 & 1.7 \\
\hline 5 & 0.433 & 2.7 & 0.287 & 1.1 & 0.154 & $0.5^{*}$ \\
\hline 26 & 0.182 & 2.2 & 0.158 & 1.2 & na & na \\
\hline
\end{tabular}


Table 8

Percent survival for larch sources in Experiment II, 1976-2019 ( $n=16$ trees for each provenance). EA=eastern/northeastern Alps; $\mathrm{SA}=$ southern Alps; SU=Sudeten.

\begin{tabular}{|c|c|c|c|c|c|c|}
\hline Source & Site & $1967^{1}$ & 1976 & 1983 & 1999 & 2019 \\
\hline 3 & High elevation; EA & 91 & 94 & 88 & 88 & 88 \\
\hline 5 & High elevation; EA & 72 & 88 & 81 & 75 & 56 \\
\hline 7 & High elevation; EA & 94 & 88 & 81 & 81 & 50 \\
\hline 8 & High elevation; EA & 97 & 100 & 100 & 94 & 56 \\
\hline 16 & High elevation; SA & 91 & 94 & 94 & 81 & 75 \\
\hline 18 & Maritime; SA & 100 & 100 & 100 & 100 & 94 \\
\hline 19 & High elevation; SA & 91 & 94 & 88 & 81 & 69 \\
\hline 20 & Maritime; SA & 91 & 100 & 100 & 69 & 69 \\
\hline 21 & High elevation; SA & 94 & 94 & 75 & 31 & 13 \\
\hline 22 & High elevation; SA & 94 & 100 & 100 & 25 & 19 \\
\hline 23 & High elevation; SA & 91 & 94 & 94 & 44 & 6 \\
\hline 24 & High elevation; SA & 91 & 100 & 88 & 88 & 63 \\
\hline 26 & High elevation; SA & 78 & 94 & 94 & 44 & 0 \\
\hline $28+$ & Plantation & 94 & 100 & 100 & 100 & 81 \\
\hline $30+$ & Plantation & 94 & 88 & 88 & 84 & 75 \\
\hline $34+$ & Plantation & 91 & 88 & 88 & 75 & 69 \\
\hline 36 & Japanese larch & 75 & 88 & 69 & 44 & 38 \\
\hline 38 & High elevation; SA & 91 & 94 & 69 & 13 & 6 \\
\hline 39 & Continental; SU & 94 & 94 & 94 & 94 & 88 \\
\hline 40 & Continental; SU & 91 & 100 & 94 & 94 & 94 \\
\hline Mean & & 90 & 95 & 89 & 71 & 55 \\
\hline
\end{tabular}

Survivorship values occurring before thinning. Data from Barnes (1977).

†Seeds obtained from a plantation; original source unknown.

steadily from $94 \%$ survival in 1976 to $6 \%$ survival in 2019 , and source 23 also reached only $6 \%$ survival in 2019, although most of its decline occurred after 1983 (Table 8). Other sources also quickly declined after having initially high rates of survival, including sources 21, 22, and 36. As in Experiment I, several sources exhibited large decreases in survival after 1999; almost half of all sources lost at least $25 \%$ of their remaining trees between 1999 and 2019, two sources (23 and 38) were reduced to a single tree, and one source (26) was eliminated from the experiment (Table 8). Survival was correlated to geographic variables (excluding the Japanese source), but only in 1999 and 2019. Survival was negatively correlated with elevation $(r=$ -0.79 and -0.84$)$, positively correlated to latitude $(r=0.7$ and $0.63)$, and negatively correlated with latitude adjusted for elevation $(-0.71,-0.83)$ in 1999 and 2019, respectively. All correlations between survival and climate variables were not significant in each of the four sample years.

\section{Growth and survival of sources common to both experiments}

There were eight sources common to both experiments (sources $3,5,7,28,34,36,39$, and 40), and their performances were consistent across the two studies. For diameter, six of the eight sources maintained their rank relative to each other within one position across all four sample years. Source 28 was the top performer of the eight sources in all sample years in Experiment I, but ranked as low as third in Experiment II. Source 39 was the fourth or fifth best performer in Experiment I, but was the top performer in most years in Experiment II. The eight sources were slightly less consistent for survival across the two experiments, with only five of the eight sources maintaining their rank within one position across the four sample years. Source 3 ranked fifth to eighth in survival in Experiment I but fourth in Experiment II. Source 36 was the second-best performer for survival in most years in Experiment I but the worst (eighth) in Experiment II. Finally, source 39 had the lowest survival rate among the eight sources in Experiment I but the third-best survival in Experiment II.

\section{Discussion}

Our data emphasize the importance of continuing provenance trials over several decades, at least approaching the typical harvest rotation period, as significant divergence in 
performances of the sources in this study did not emerge until at least 40 years after the provenance trial began. Although many of the initial trends reported by Barnes (1977) were consistent throughout the 43 years that followed that study, important changes occurred in survival and growth that cannot be explained by tree age alone. Genetic variation revealed by long-term provenance trials is of the utmost importance for forest management (Ying and Morgenstern 1988), particularly when such management addresses forest tree species' survival and growth as an attempt to confront climate change (Lu et al. 2016, Leech et al. 2011, Hamaan et al. 2011).

\section{Variation in survival}

Relative performances of provenances in both experiments varied more for survival than for growth from those reported by Barnes (1977) for tree ages at 19 years. At that stage of the experiments, survival was $>92 \%$ for all sources except sources $2,7,36$, and Dunkheld, attributed to their planting in a frost pocket in Experiment I (Barnes 1977). Extension of the experiments for an additional 43 years suggested some divergence from these trends as survival of some sources began to decrease by 1983 ( 25 years from seed) and more than half of the sources experienced significant mortality after 1999 (41 years from seed). These results are consistent with those of many older provenance trials that showed substantial changes in performance among provenances that occur approximately halfway through the rotation period (25-30 years in this study; Morgenstern and Mullin 1990, Campbell 1974, Dietrichson 1964), even when their early survival was high. Importantly, initial results presented by Barnes (1977) suggested much higher adaptability of provenances to the growing environment in southeastern Michigan because differences in survival among provenances had not yet emerged at that time. Continental sources from the Czech Republic (sources 39 and 40) had excellent overall survival in both experiments, presumably because the original continental climate (with higher summer high temperatures and colder winter low temperatures) and latitude of those sources are similar to those of the planting site (Barnes 1977). Trees from the Schlitz plantation (source 28) and one maritime source (18) had the overall best survival in either experiment. Poorer survivors were high-elevation sources and the Japanese larch (36) in both experiments.

Causes of tree mortality in this study are only speculative, but the differences in survival among sources may have been caused by extreme climate events that occurred since the 1970s (Barnes et al. 1998, Morgenstern and Mullin 1990, Campbell 1974, Namkoong et al. 1972), most likely occasional ice storms and drought events either individually or in combination. For example in Experiment II, almost half of all sources lost at least $25 \%$ of their remaining trees between 1999 and 2019, two sources ( 23 and 38 ) were reduced to a single tree, and one source (26) was eliminated from the experiment (Table 8). Barnes (1977) noted a significant spring ice storm that damaged and/or killed trees of certain sources in 1976 and attributed the differential damage to crown shape of the respective provenances. Barnes (1977) also noted major ice damage in 1976 on sources 21 and 38, and both exhibited large decreases in survival between 1976 and 1983 and between 1983 and 1999 . The Japanese source (36), with a wide-spreading crown, was most heavily damaged by this storm and exhibited poor survival throughout the remainder of both experiments. Similar ice storms affected the study area in 1985, 2003, and 2013 and may have affected the survival of the Japanese larch, but several higher-elevation sources - presumably with crown architecture less susceptible to ice damage - exhibited lower survival by 2019 than did the Japanese larch, suggesting that ice storms were not the sole driver of mortality in the study. In addition, survival was moderately correlated to elevation in the latter years of Experiment II, but uncorrelated to elevation in all years in Experiment l, such that the importance of elevation in determining morphological traits that would make a provenance more or less susceptible to ice storms is not obvious.

European larch has been documented to be sensitive to drought events that create significant soil water deficits (George et al. 2016, Levesque et al. 2013, Eilmann and Rigling 2012), and this sensitivty varies widely among provenances (George et al. 2016). Drought tolerance has been shown to vary among populations of other species as well as European larch (Gaspar et al. 2013, Arend et al. 2011). In this study, seven significant drought events during the growing season occurred after 1976 that are likely to have been a major influence on the survival of provenances by 2019. These events were represented as at least two consecutive monthly scores $<-2.0$ on the Palmer Drought Severity Index (PDSI) for the study area (www.drought. gov accessed 6-15-2020). The most severe of these events occurred from May-July 1977, when PDSI was <-4.2 for at least 90 consectutive days. Aside from source 36 (mortality assumed to be related to ice damage), significant reductions in survival occurred in sources 21, 24, and 38 (all high-elevation provenances) between 1976 and 1983 that may be related to the 1977 drought. Similar but less severe events occurred approximately twice per decade thereafter: May-July 1987, June-July 1988, July-September 1998, May-June 1999, May-Sept 2005, and July-September 2007. Given the poor and relatively dry soils of the study site, these droughts may explain the large decrease in survival for many high-elevation sources, presuming that droughts are less frequent and severe in high-elevation environments and provenances there are presumably less drought resistant (George et al. 2016). Notably, at least 6 highelevation sources in this study experenced high mortality between 1983 and 1999, and 14 between 1999 and 2019.

A third factor that may have affected tree mortality is density-dependent mortality, particularly in Experiment I which was not thinned. European larch is shade-intolerant, and initial planting density in Experiment I exceeded 1700 stems/ha when recent research recommends initial densities of 990 stems/ha (Carter and Selin 1987). However, we noted few spatial patterns of mortality in 2019 that would suggest an effect of density-dependent mortality; instead, we noted a regular pattern of tree spacing due to planting and only marginal canopy closure even 61 years after planting. Only two of the eight sources common to both experiments (sources 3 and 39) showed improvement in survival relative to one another from the unthinned Experiment I to the thinned Experiment II 
(Tables 5, 7). Furthermore, mortality within provenances in Experiment I was not necessarily consistent among blocks (e.g., sources 2, 7, and 36, which experienced high mortality in one block of Experiment l, did not exhibit similar levels of mortality in the other block), suggesting that mortality is likely driven by allogenic rather than autogenic processes. While it is likely that ingrowth of non-experimental, shade-tolerant, deciduous trees into the experiment will eventually outcompete experimental larch, current non-experimental trees remain largely in the subcanopy and are not likely to have outcompeted experimental larch as of 2019.

\section{Variation in growth}

Differences in diameter growth among provenances were most pronounced in 1976 and 1999 for Experiment I, and in Experiment II were most pronounced in 1983. The best performing provenances achieved nearly double or more the growth in diameter of the poorest performing provenances. In 1976, plantation sources (28 and 30) and continental sources ( 39 and 40) were the top performers, and these sources exhibited the best diameter growth through 2019. Notably, the Schlitz plantation (28) remained the best performer in Experiment I ( $n=$ 144 per source) in every sample year. Plantation sources, despite their unknown origins, were probably good performers because of their likely reduced amount of inbreeding in a controlled growing environment and their improved stock created by selective thinning (Barnes 1977). The poorest performers for growth included exclusively French, Austrian, and Italian highelevation sources that performed poorly beginning in 1976 (Barnes 1977); these sources were presumably slower-growing because of their adaptation to shorter growing seasons at their original sites. However, the poorest performers for growth were also mostly from the southern Alps, a group of alpine larch with typically poor form and slow growth (Pâques et al. 2013). Elevation was moderately strongly correlated with DBH in sample years before 2019, but climate variables were inconsistent in their correlation to DBH. The best performing sources most often originated from lower elevations, similar to that in southeastern Michigan, but originated from more northerly latitudes than the study site, suggesting that macroclimate at the original sites is only partially responsible for provenance performance. These results corroborate those of many others who have shown variation in growth among provenances (e.g., Lu et al. 2014, Wang et al. 2010, Morgenstern \& Mullin 1990).

Earlier results of both the First and Second International Larch Provenance Tests (Schober 1985, 1981) suggest that broad groups of European larch provenances may be better predictors of performance compared to geographic variables such as elevation and latitude or macroclimate variables of summer and winter temperature and summer precipitation, at least for growth. As summarized by Pâques et al. (2013), Alpine larch may be divided into four subgroups among which growth varies substantially: the southern Alps, where larch occurs over a very wide range of elevations and whose provenances exhibit slow growth; the central Alps, which include very harsh growing conditions and short growing seasons at high altitudes; the northern Alps, where growth is variable among provenances; and the northeastern and eastern Alps, characterized by lower and submontane altitudes with the best growth potential compared to the other Alpine larches. By comparison, the Sudeten provenances of larch grow faster than those of the Alps, and these larch are known for their ability to grow well on many different sites (Pâques et al. 2013) and their success in North America (Gilmore and David 2002). Such characterizations explain at least some of the variation found in this study. For example, the Sudeten sources in our study (sources 39 and 40) were consistently among the best growing sources in both experiments whose origin was known. In addition, of the Alpine provenances, source 3 - from the northeastern Alps - was among the best performers for growth in both experiments. Likewise, most of the consistently poorest growers in Experiment II, such as sources 21, 22, 23, 26, and 38, were all from the southern Alps which produce provenances characterized by slow growth (Pâques et al. 2013). Two notable exceptions are the Langau sources (sources 5 and 7), which originate in northern Austria along the border with the Czech Republic. This location is east of the Alps and south of the Sudetes, both regions that produce relatively fast-growing provenances (Pâques et al. 2013, Schober 1985, 1981). However, sources 5 and 7 were consistently among the poorest growing provenances in both experiments; this unusual location for European larch, its poor growth in spite of its nearby fast-growing provenances, and the prevalence of human-influenced disjunct populations of European larch (Wagner et al. 2015 a, 2015 b, Pâques et al. 2013) raise the possibility that the Langau sources were translocated there by humans in the recent past from locations with slow-growing larch. As summarized by George et al. (2016), abundant evidence exists that human movement of European larch sources has been significant since the early 1700s (Jansen and Gaburek 2016, Wagner et al. 2015); such translocation would make it difficult to easily associate the provenance with its source climate without extensive genetic analysis.

Interestingly, growth patterns of the provenances varied over the sampling intervals (as evidenced by repeated measures ANOVA), but the rate of initial growth was the often strongest driver of tree diameter after 61 years of the provenance trial. For example, source 28 in Experiment I was the best performer in growth overall, but much of this appears to have been accomplished early in the sample period (between 1976 and 1983) when basal area growth was well above average, as growth thereafter was either average or below average (Table 4). Similarly, sources 2 and 7 had periods of higher-than-average growth ( 2 between 1983 and 1999, and 7 between 19992019), but relatively slow initial growth prior to 1976 limited their performance over the long term. In Experiment II source 21 had higher-than average growth between 1983 and 1999, source 22 between 1976 and 1999, and source 38 between 1983 and 2019, but all three were among the worst performers in terms of growth because of poor initial growth. Notably, Barnes (1977) reported height growth to be among the slowest for sources 2 and 7 in Experiment I in 1967, and for sources 21, 22, and 38 in 1967 for Experiment II. The drivers of this variation in growth rate for certain sources are unclear; the occurrence of 
drought or ice storms in the study area is not sufficient to explain the increased growth rate of many poor-performing sources corresponding in time with such events. All the sources in question were high-elevation sources, perhaps suggesting local adaptations to their original sites in dissected topography that might make those sources less susceptible to ice storms or drought in southeastern Michigan, or other unique aspects of the origin site that are not cleanly captured within macroclimate (George et al 2016) or geographic variables. Alternatively, the larch provenances in this study may simply be weakly adapted to their local sites or not adapted at all, as has been suggested for many herbaceous plant species (e.g., Bucharova et al. 2017, Breed et al. 2013, Jones 2013), or translocation of local populations by humans may have occurred (Jansen and Gaburek 2016, Wagner et al. 2015). Clearly, although it is the typically metric used to determine growth performance of provenances, DBH or wood volume at the rotation age does not adequately capture variations in growth rate that may occur over several decades for a given provenance.

\section{Caveats and considerations}

Despite the benefits of a long-term provenance trial, the experimental design presented in this study includes some important limitations. First, our study is limited to a single test site, and the inevitable effect of site variability on larch survival and particularly growth (Gilmore and David 2002) has not been captured even by the randomized complete-block design. Second, our attempts to relate survival to local adaptation of the provenances were complicated by the establishment of non-experimental trees into the plantation. The open planting design is an ideal light environment for gap or edge species such as black cherry or mesic colonizers such as American elm; though still in the subcanopy, these trees will soon reach a height that will overtop and/or suppress larch that are part of the provenance trial. In addition to Norway maple, an invasive tree whose establishment also impacts the persistence of shade-intolerant larch, the presence of these species will soon impact the survival of trees in a manner unrelated to their provenance, if it has not already done so. Third, we were unable to document the impacts of insects or diseases that may have caused differences in growth or survival since 1976. Barnes (1977) noted differences among sources in their susceptibility to severe infestations of the larch casebearer (Coleophora laricella Hübner) and the presence of the larch wooly aphid (Chermes strobilobious Kalt.) during the first 19 years of the study, and Gilmore and David (2002) have summarized notable differences in susceptibility to insects and diseases among the broad subgroups of European larch. It is possible that insect and potentially pathogenic infestations have differentially impacted growth and survival across the experiments in this study. Finally, the original experimental design of this study did not include a local provenance of European larch. The lack of a locally adapted provenance for comparison to those from European sources limits our ability to explain differences in survival and growth among provenances at the study site in southeastern Michigan.

\section{Conclusions}

Our study suggests that provenance trials are valuable sources of data that, when maintained and sampled over long periods of time, may show divergence in growth and survival from early or even mid-term results. Such long-term experiments are optimal when assessments are repeated over the course of the trial and, ideally, the specific cause of mortality identified where possible (Morgenstern and Mullin 1990). Our data suggest that survival data are likely to be much more reliant on longterm trials than growth data, as the latter appears to be fairly consistent from early results (19 years from seed) to those in 2019. As survival of provenances over the long term is likely directed by the occurrence of extreme climate events at the site of the provenance trial (in our case ice storms and recurring droughts), such survival data will be critical in predicting species' response to climate change and will perhaps play an important role in strategies for its mitigation.

\section{Acknowledgements}

This work was supported by the Department of Biological Sciences at Wayne State University. We gratefully acknowledge the hard work by our field crews over 43 years, including some who thought they may have safely slipped into obscurity: Mike Bosio, D. D'Amore, Jenn Tomkow-Demaestri, Robbie DuVuyst, Dr. David Hix, Amelia Kashian, Colter Kashian, Deb Livingston, D. Nagle, Dr. Tom Spies, Val Spooner, and Dr. Alan Tepley. We also wish to thank the undergraduate and graduate students of the Forest Ecology (NR 435) course at the University of Michigan in the 1970s, 80s, and 90s, whose enthusiasm and interest maintained this study annually through frigid December field labs. Author contributions: BVB maintained the original study and collected data in 1976, 1983, and 1999; DMK collected data in 2019, analyzed data, and wrote the manuscript.

\section{References}

Aitken SN, Yeaman S, Holliday JA, Wang T, Curtis-McLane S (2008) Adaptation, migration or extirpation: climate change outcomes for tree populations. Evolutionary Applications 1:95-111.

https://doi.org/10.1111/j.1752-4571.2007.00013.x

Arend M, Kuster T, Günthardt-Goerg MS, Dobbertin M (2011) Provenance-specific growth responses to drought and air warming in three European oak species (Quercus robur, Q. petraea and Q. pubescens). Tree Physiology 31: 287297. https://doi.org/10.1093/treephys/tpr004

Barnes BV, Zak DR, Denton S, Spurr SH (1998) Forest Ecology, $4^{\text {th }}$ edition. John Wiley and Sons.

Barnes BV (1977) The International Larch Provenance Test in southeastern Michigan, USA. Silvae Genetica 26: 145-148.

Breed MF, Stead MG, Ottewell KM, Gardner MG, Lowe AJ (2013) Which provenance and where? Seed sourcing strategies for revegetation in a changing environment. Conservation Genetics 14: 1-10. https://doi.org/10.1007/s10592-012-0425-z

Bucharova A, Durka W, Holzel N, Kollmann J, Michalski S, Bossdorf O (2017) Are local plants the best for ecosystem restoration? It depends on how you ana- 
lyze the data. Ecology and Evolution 7: 10683-10689.

https://doi.org/10.1002/ece3.3585

Campbell RK (1979) Genecology of Douglas-fir in a watershed in the Oregon cascades. Ecology 60: 1036-1050. https://doi.org/10.2307/1936871

Campbell RK (1974) A provenance-transfer model for boreal regions. Medd. Nor Inst. Skogforsk. 31: 542-566.

Carter KK, Selin LO (1987) Larch plantation management in the Northeast. Northern Journal of Applied Forestry 4: 18-20. https://doi.org/10.1093/njaf/4.1.18

Cook DB (1955) Improvement of larch by selection of species and geographic races. New York Forester 12: 11-13.

Dietrichson J (1964) The provenance problem illustrated by studies of growthrhythm and climate. Medd. Nor. Skogforsoksves. Nr. 71. Bd. 19. H:5. Pp. 505656

Eilmann B, Rigling A (2012) Tree-growth analyses to estimate tree species drought tolerance. Tree Physiology 32: 178-187. https://doi.org/10.1093/treephys/tps004

Gaspar MJ, Velasco T, Feito I, Alía F, Majada J (2013) Genetic variation of drought tolerance in Pinus pinaster at three hierarchical levels: a comparison of induced osmotic stress and field testing. PlosOne 8: 1-10 https://doi.org/10.1371/journal.pone.0079094

George J-P, Grabner M, Karanitsch-Ackerl S, Mayer K, Weißenbacher L, Schueler S (2016) Genetic variation, phenotypic stability, and repeatability of drought response in European larch throughout 50 years in a common garden experiment. Tree Physiology 37: 33-46. https://doi.org/10.1093/treephys/tpw085

Giertych M, Oleksyn J (1981) Summary of results on Scots pine (Pinus sylvestris L.) volume production in Ogievskij's pre-revolutionary Russian provenance experiments. Silvae Genetica 30: 56-74.

Gilmore DW, David AJ (2002) Current trends in management practices for European larch in North America. Forestry Chronicle 78: 822-829. https://doi.org/10.5558/tfc78822-6

Hamann A, Gylander T, Chen P-Y (2011) Developing seed zones and transfer guidelines with multivariate regression trees. Tree Genetics and Genomes 7 : 399-408. https://doi.org/10.1007/s11295-010-0341-7

Hereford J (2009) A quantitative survey of local adaptation and fitness tradeoffs. The American Naturalist 173: 579-588.https://doi.org/10.1086/597611

Hunt SS (1932) European larch in the northeastern United States. Harvard Fores Bulletin Number $16,45 \mathrm{pp}$.

Jansen S, Geburek T (2016) Historic translocations of European larch (Larix decidua Mill.) genetic resources across Europe - A review from the 17th until the mid-20th century. Forest Ecology and Management 379: 114-123. https://doi.org/10.1016/j.foreco.2016.08.007

Jones TA (2013) Ecologically appropriate plant materials for restoration applications. BioScience 63: 211-219. https://doi.org/10.1525/bio.2013.63.3.9

Leech SM, Almuedo PL, O'Neill G (2011) Assisted migration: adapting forest management to a changing climate. $\mathrm{BC}$ Journal of Ecosystems and Management 12: 18-34.

Leimu R, Fischer M (2008) A meta-analysis of local adaptation in plants. PLoS ONE 3: e4010. https://doi.org/10.1371/journal.pone.0004010

Levesque M, Saurer M, Siegwolf R, Eilmann B, Brang P, Bugmann H, Rigling A (2013) Drought response of five conifer species under contrasting water availability suggests high vulnerability of Norway spruce and European larch. Global Change Biology 19: 3184-3199. https://doi.org/10.1111/gcb.12268

Lu P, Parker WC, Colombo SJ, Man R (2016) Restructuring tree provenance test data to conform to reciprocal transplant experiments for detecting local adaptation. Journal of Applied Ecology 53: 1088-1097. https://doi.org/10.1111/1365-2664.12647

Lu P, Parker WH, Cherry M, Colombo S, Parker WC, Man R, Roubal N (2014) Survival and growth patterns of white spruce (Picea glauca [Moench] Voss) range wide provenances and their implications for climate change adaptation. Ecology and Evolution 4: 2360-2374. https://doi.org/10.1002/ece3.1100

McComb AL (1955) The European larch: its races, site requirements and characteristics. Forest Science 1: 298-318.

Morgenstern EK, Mullin TJ (1990) Growth and survival of black spruce in the range wide provenance study. Canadian Journal of Forest Research 20: 130143. https://doi.org/10.1139/x90-019
Namkoong G, Usanis RA, Silen RR (1972) Age-related variation in genetic contro of height growth in Douglas-fir. Theoretical and Applied Genetics 42: 151 159. https://doi.org/10.1007/bf00280791

Nienstaedt $\mathrm{H}$ (1979) The role of provenance tests in tree improvement. In: Proceedings of the $17^{\text {th }}$ Meeting of the Canadian Tree Improvement Association, Gander, August 27-30, 1979. Canadian Forestry Service, Ottawa. pp. 15-25.

Oleksyn J, Giertych M (1984) Results of a 70 year old Scots pine (Pinus sylvestris L.) provenance experiment in Pulawy, Poland. Silvae Genetica 33: 22-27.

Pâques L, Foffová E, Heinze B (2013) Larches (Larix sp.). In: Pâques L. (ed). Forest tree breeding in Europe-current state-of-the-art and perspectives. Springer, Dordrecht, pp 13-122.https://doi.org/10.1007/978-94-007-6146-9 2

Rehfeldt GE, Ying CC, Spittlehouse DL, Hamilton DA (1999) Genetic responses to climate in Pinus contorta: niche breadth, climate change, and reforestation. Ecological Monographs 69: 375-407. https://doi.org/10.2307/2657162

Sang Z, Sebastian-Azcona J, Hamann A, Menzel A, Hacke U (2019) Adaptive limitations of white spruce populations to drought imply vulnerability to climate change in its western range. Evolutionary Applications 12: 1850-1860. https://doi.org/10.1111/eva.12845

Savolainen O, Pyhajarvi T, Knurr T (2007) Gene flow and local adaptation in trees. Annual Review in Ecology, Evolution, and Systematics. 38: 595-619. https://doi.org/10.1146/annurev.ecolsys.38.091206.095646

Schober R (1985) Neue Ergebnisse des II. Internationalen Lärchenprovenienzversuch von 1958/59 nach Aufnahmen von Teilversuchen in 11 europäïschen Ländern und den USA. J.D. Sauerlander's Verlag, Frankfurt am Main, 168 pp.

Schober R (1981) On the first international larch provenance trail 1944. Report on three German trials. Part I. Part II. Part III. (Vom I. Internationalen Lärchenprovenienzversuch 1944. Bericht uber drei deutsche Teilversuche. Teil I. Teil II. Teil III.) Allgemeine Forst- und Jagdzeitung 152: 181-195, 201-211, 221233.

Schober R (ed) (1977) Vom zweiten internationalen Lärchenprovenienzversuch. In: Ein Beitrag zur Lärchenherkunftsfrage. Sauerlaender Verlag, Frankfurt.

Schober R (1976) Vom 2. Internationalen Lärchenprovenienzversuch, Begründe 1958/59. Pp 162-173. In: Proceedings of the XVI IUFRO World Congress, Division II. Norway.

Thomson AM, Parker WH (2008) Boreal forest provenance tests used to predict optimal growth and response to climate change. 1. Jack Pine. Canadian Journal of Forest Research 38: 157-170. https://doi.org/10.1139/x07-122

Wagner S, Litt T, Sanchez-Goni MF, Petit RJ (2015a) History of Larix decidua Mill. (European larch) since 130ka. Quaternary Science Review 124: 224-247. https://doi.org/10.1016/j.quascirev.2015.07.002

Wagner S, Liepelt S, Gerber S, Petit RJ (2015b) Within-range translocations and their consequences in European larch. PLoS ONE 10:1-17. https://doi.org/10.1371/journal.pone.0127516

Wang T, O'Neill GA, Aitken SN (2010) Integrating environmental and genetic effects to predict responses of tree populations to climate. Ecological Applications 20: 153-163. https://doi.org/10.1890/08-2257.1

Wang T, Hamann A, Yanchuk A, O'Neill GA, Aitken SN (2006) Use of response functions in selecting lodgepole pine populations for future climates. Global Change Biology 12: 2404-2416. https://doi.org/10.1111/j.1365-2486.2006.01271.x

Wiersma JH (1963) A new method of dealing with results of provenance tests. Silvae Genetica 12: 200-205.

Ying CC, Morgenstern EK (1988) The status of provenance research in Canada. In: Proceedings of the 21st Meeting of the Canadian Tree Improvement Association, Truro, N.S., August 17-21, 1987. Part 2. Canadian Forestry Service, Ottawa. pp. 1-19. 